Proc. XIX International School of Semiconducting Compounds, Jaszowiec 1990

\title{
THE PRESSURE DEPENDENCE OF TRANSITION METAL-RELATED LEVELS IN GaAs*
}

\author{
A. Babiński, M. Baj and A.M. Hennel \\ Institute of Experimental Physics, Warsaw University, Hoża 69, 00-681 Warszawa, \\ Poland
}

(Received August 8, 1990)

\begin{abstract}
The hydrostatic pressure coefficients of $\mathrm{V}^{3+/ 2+}$ acceptor level in bulk GaAs and of the $0.48 \mathrm{eV}$ trap (related to $\mathrm{Ni}^{2+/ 1+}$ double acceptor level) in VPE GaAs were measured by means of the DLTS technique. The obtained values are $94 \mathrm{meV} / \mathrm{GPa}$ and $196 \mathrm{meV} / \mathrm{GPa}$ relative to the bottom of the conduction band. For $\mathrm{Ni}^{2+/ 1+}$ level the strong pressure dependence of the capture cross-section activation energy $(60 \mathrm{meV} / \mathrm{GPa})$ was also observed.
\end{abstract}

PACS numbers: 71.55.Eq, 62.50.+p

It is known that transition metal (TM) levels in compound scmiconductors can act as reference levels, from which heterojunction band lineups can be calculated $[1,2]$. Adopting the concept of such reference level, it was proposed that TM levels absolute energies (i.e. vacuum related) should be insensitive to stress [3]. Thus, the pressure coefficients of TM levels related to conduction band or valence band edge could be used to calculate the band-edge deformation potential [3]. However, it was found from the uniaxial-stress DLTS measurements that the hydrostatic pressure coefficient (relative to the bottom of the conduction band) for $\mathrm{Ni}^{2+/ 1+}$ level in GaAs was $34 \%$ larger than for the $\mathrm{Ti}^{3+/ 2+}$ and $\mathrm{V}^{3+/ 2+}$ levels in the same material [4]. Therefore, the aim of this work was to measure the hydrostatic pressure coefficients of $\mathrm{V}^{3+/ 2+}$ level and of the $0.476 \mathrm{eV}$ trap (usually related to $\mathrm{Ni}^{2+/ 1+}$ level). These coefficients were measured in the DLTS experiment performed under hydrostatic pressure.

The samples investigated in this work were prepared from two materials: vanadium doped HB GaAs $\left(n=3 \times 10^{15} \mathrm{~cm}^{-3}\right)$ grown at MIT (USA) and undoped VPE GaAs $\left(n=2.5 \times 10^{15} \mathrm{~cm}^{-3}\right)$ grown in ITME, Warsaw. The DLTS measurements were performed on Au-Schottky diodes placed in a high pressure cell with a benzine as a pressure transmitting medium. Hydrostatic pressure up

*This work was supported by CPBP 01.05. 

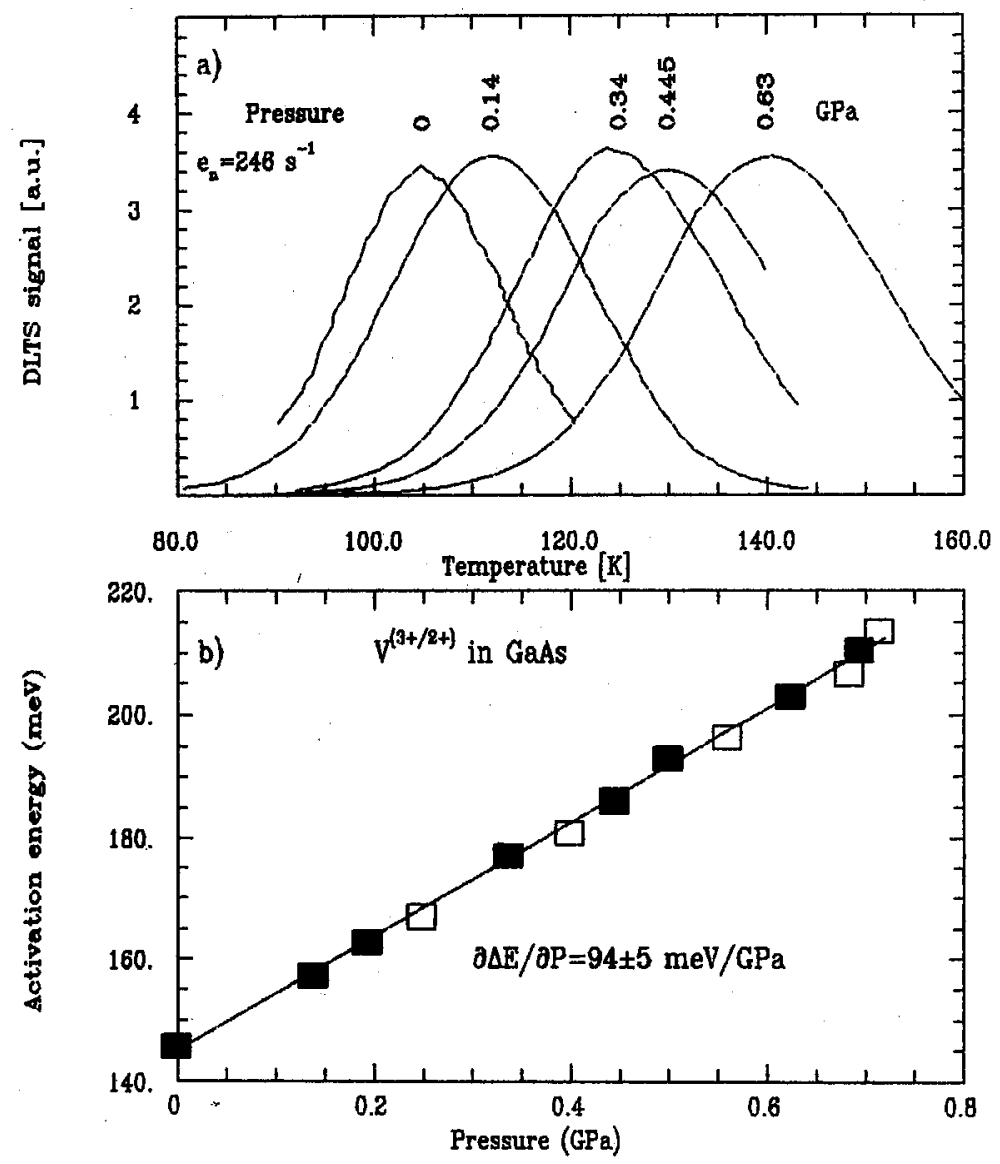

Fig. 1. a) DLTS spectra for $\mathrm{V}^{3+/ 2+}$ acceptor level in GaAs $(\Delta E=0.146 \mathrm{eV})$ under hydrostatic pressure; the emission rate window $e_{n}=246 \mathrm{~s}^{-1}$; b) the pressure dependence of $\mathrm{V}^{3+/ 2+}$ level activation energy; full and empty squares correspond to the values obtained with $e_{n}=246 \mathrm{~s}^{-1}$ and $e_{n}=2470 \mathrm{~s}^{-1}$, respectively. 

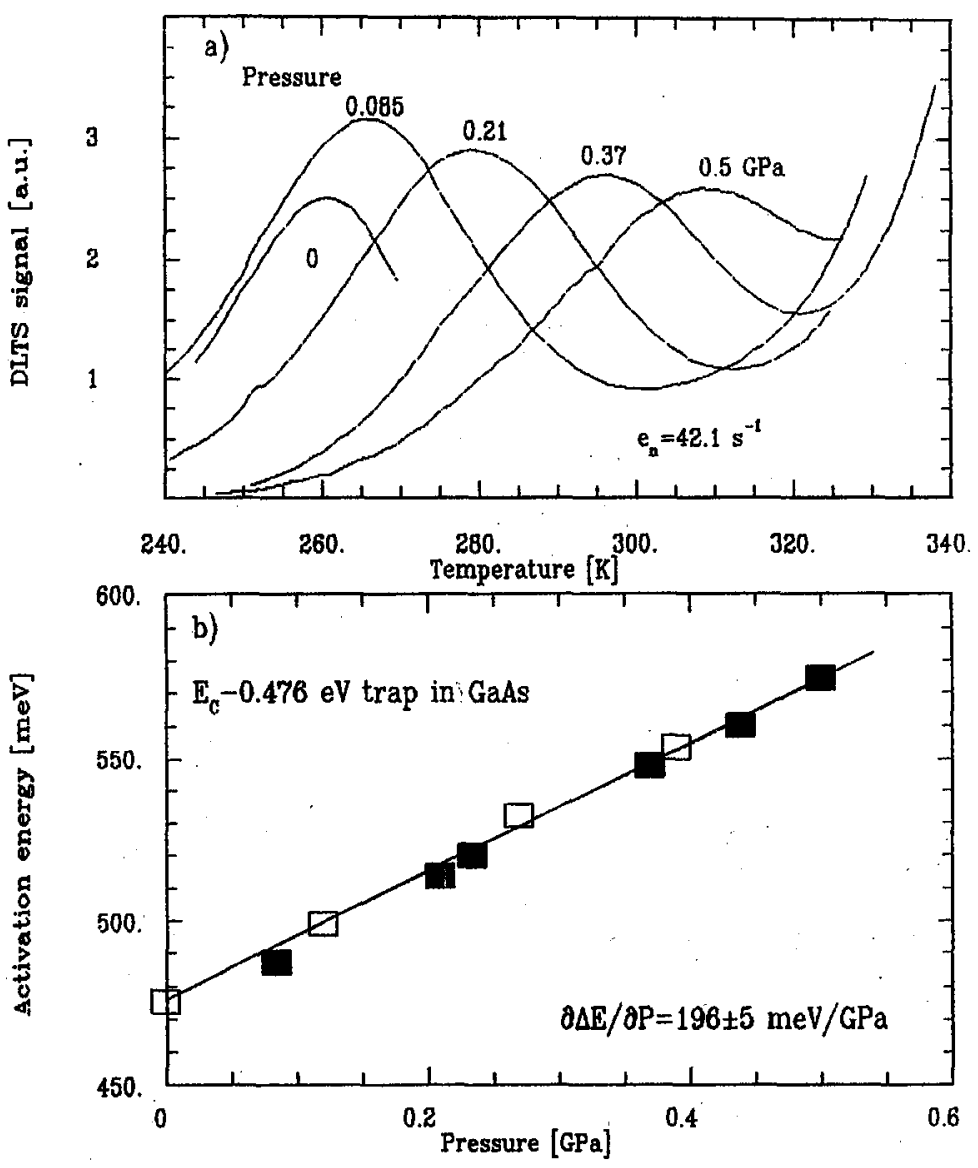

Fig. 2. a) DLTS spectra for $0.476 \mathrm{eV}$ trap related to $\mathrm{Ni}^{2+/ 1+}$ double acceptor level in GaAs under hydrostatic pressure; the emission rate window $e_{n}=42.1 \mathrm{~s}^{-1}$; b) the pressure dependence of emission rate activation energy for $0.48 \mathrm{eV}$ trap; full and empty squares correspond to the values obtained with $e_{n}=42.1 \mathrm{~s}^{-1}$ and $e_{n}=246 \mathrm{~s}^{-1}$, respectively. 
to $0.7 \mathrm{GPa}$ was measured with a calibrated $\mathrm{InSb}$ manometer. The signature of investigated levels (i.e. $\Delta \mathrm{E}$ - the emission rate activation energy and $\sigma_{\infty}$ - the capture cross-section) were obtained from measurements under atmospheric pressure. The activation energies of the investigated levels under hydrostatic pressure were extracted from the DLTS-peak shifts with the emission rate window kept constant. The pressure coefficients of the capture cross-section activation energies were obtained by measurements of the DLTS peak-height dependence on a pulse duration time at a specific temperature under several pressures.

The value of the activation energy $(\Delta E=0.146 \mathrm{eV})$ of the main trap in the DLTS spectrum of vanadium doped sample was in good agreement with the value reported for $\mathrm{V}^{3+/ 2+}$ level in the same material $(\Delta E=0.15 \mathrm{eV})[5]$. The DLTS spectra recorded under several values of pressure are presented in Fig. 1a. Because the value of pressure depended on temperature, the curves in Fig. 1a are marked with the pressure values corresponding to the DLTS peaks. The pressure derivative of $\Delta E$ for $V^{3+/ 2+}$ level in GaAs was found to be equal to $94 \pm 5 \mathrm{meV} / \mathrm{GPa}$ (see Fig. 1b). No pressure dependence of the capture cross-section activation energy was observed.

In the second sample i.e. undopped VPE GaAs two main peaks in the DLTS spectrum were observed $(\Delta E=0.476 \mathrm{eV}, \Delta E=0.82 \mathrm{eV})$. The value of the activation energy of $0.476 \mathrm{eV}$ trap was in good agreement with $\Delta E$ proposed for $\mathrm{Ni}^{2+/ 1+}$ double acceptor in GaAs $(\Delta E=0.48 \mathrm{eV}[6,7])$. Moreover, the nickel contamination is usually observed in hydride VPE materials $[8,9]$. Both of these facts strongly support attribution of the $0.476 \mathrm{eV}$ trap to the $\mathrm{Ni}^{2+11+}$ double acceptor level. The DLTS spectra obtained under several values of pressure are presented in Fig. 2a while the pressure dependence of $\Delta E$ is shown in Fig. 2b. The pressure derivative of $\Delta E$ was found to be equal to $196 \pm 5 \mathrm{meV} / \mathrm{GPa}$. The strong pressure dependence of the capture cross-section activation energy was observed. Its pressure derivative obtained from measurements performed at $T=302 \mathrm{~K}$ was $60 \pm 10 \mathrm{meV} / \mathrm{GPa}$.

The value of the pressure coefficient for both $\mathrm{Ti}^{3+/ 2+}$ and $\mathrm{V}^{3+/ 2+}$ levels evaluated from the data published recently [3] is equal to $116 \pm 12 \mathrm{meV} / \mathrm{GPa}$. The difference between this value and the value obtained by us $(94 \pm 5 \mathrm{meV} / \mathrm{GPa})$ is slight above the experimental error. It was found [4] that the pressure derivative of $\mathrm{Ni}^{2+/ 1+}$ level was equal to $1.34 \times 116 \mathrm{meV} / \mathrm{GPa}=155 \mathrm{meV} / \mathrm{GPa}$ and the capture cross-section activation energy did not depend on the pressure. The pressure derivative of $\mathrm{Ni}^{2+/ 1+}$ level ionization energy obtained by us was equal to $136 \pm 15 \mathrm{meV} / \mathrm{GPa}$ and the capture cross-section activation energy exhibited the strong pressure dependence $(60 \pm 10 \mathrm{meV} / \mathrm{GPa})$.

Our results point out the significant role of the pressure dependence of the capture cross-section in the interpretation of the pressure coefficient measurements of TM levels. Moreover, it seems that the DLTS under hydrostatic pressure is more effective tool for the measurements of the deep level hydrostatic pressure coefficients than uniaxial-stress experiments. 


\section{References}

[1] M.J. Caldas, A. Fazzio, A. Zunger, Appl. Phys. Lett. 45, 671 (1984).

[2] J.M. Langer, H. Heinrich, Phys. Rev. Lett. 55, 1414 (1985).

[3] D.D. Nolte, W. Walukiewicz, E.E. Haller, Phys. Rev. Lett. 59, 4, 501 (1987).

[4] D.D. Nolte, W. Walukiewicz, M. Hamera, E.E. Haller, in Proc. 19th Internat. Conf. on the Physics of Semiconductors, Warsaw 1988, ed. W. Zawadzki, Institute of Physics, Polish Academy of Sciences, Warsaw 1988, Vol. 2, p. 893.

[5] A.M. Hennel, C.D. Brandt, K.Y. Ko, J. Lagowski, H.C. Gatos, J. Appl. Phys. 62, 163 (1987).

[6] S. Brehme, R. Pickenhain, Solid State Commun. 59, 469 (1986).

[7] D.L. Partin, J.W. Chen, A.G. Milnes, L.F. Vassamillet, J. Appl. Phys. 50, 6845 (1979).

[8] B. Dienger, H. Weinert, R. Pickenhain, W. Hörig, Phys. Status Solidi A 97, 313 (1986).

[9] R.E. Enström, J.R. Appert, J. Electrochem. Soc. 129, 2566 (1982). 